
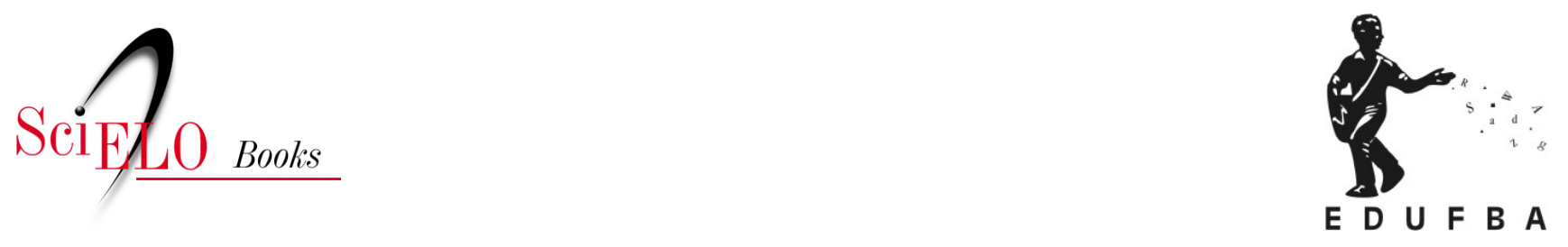

\title{
13 Tribo Liabeae (Cass. ex Dumort.) Rydb.
}

\author{
Giselle Lopes Moreira \\ Cellini Castro de Oliveira
}

MOREIRA, G.L., and OLIVEIRA, C.C. Tribo Liabeae (Cass. ex Dumort.) Rydb. In: ROQUE, N. TELES, A.M., and NAKAJIMA, J.N., comp. A família Asteraceae no Brasil: classificação e diversidade [online].

Salvador: EDUFBA, 2017, pp. 97-99. ISBN: 978-85-232-1999-4.

https://doi.org/10.7476/9788523219994.0015.

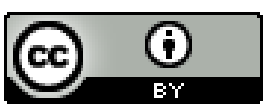

All the contents of this work, except where otherwise noted, is licensed under a Creative Commons Attribution 4.0 $\underline{\text { International license. }}$

Todo o conteúdo deste trabalho, exceto quando houver ressalva, é publicado sob a licença Creative Commons Atribição 4.0. 


\title{
TRIBO LIABEAE (CASS. EX DUMORT.) RYDB.
}

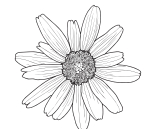 \\ Giselle Lopes Moreira \\ Cellini Castro de Oliveira
}

A história da classificação de Liabeae reflete a dificuldade de agrupamento dos seus táxons desde os naturalistas, entre eles, Cassini (1923), Bentham (1873) e Hoffmann (1890), que variavelmente trataram os grupos como membros de Vernonieae, Senecioneae, Heliantheae, Helenieae e Mutisieae.

Embora Rydberg (1927) tenha proposto formalmente o status de tribo para cinco gêneros (Liabum Adans, Sinclairiopsis Rydb., Megaliabum Rydb., Liabellum Rydb. e Sinclairia Hook. \& Arn.), trabalhos taxonômicos e florísticos (CARLQUIST, 1976; CRONQUIST, 1955) continuaram a adotar a classificação de Bentham, na qual a maioria dos táxons foi incluída apenas no gênero Liabum, tribo Senecioneae. A partir dos trabalhos conduzidos por Robinson (1983a, 1983b, 1990a, 1990b, 1994) e Robinson e Brettell (1973, 1974), a tribo Liabeae foi recircunscrita com o reconhecimento de três subtribos, 15 gêneros e cerca de 157 espécies.

Segundo Dillon e colaboradores (2009), Liabeae pode ser reconhecida por um conjunto de caracteres, tais como: presença de látex, folhas geralmente opostas, frequentemente trinervadas e alvo-tomentosas na face abaxial, capítulos radiados e heterógamos, corola das flores do raio e do disco comumente amarela, pápus geralmente duplo, série mais externa de escamas curtas e a mais interna de cerdas escabrosas e maiores.

Atualmente, Liabeae representa uma das menores tribos da família, com 18 gêneros e cerca de 165 espécies, com distribuição inteiramente neo- 
tropical, tendo o Peru como centro de diversidade, onde ocorrem 13 dos 18 gêneros reconhecidos (DILLON et al., 2009).

\section{Descrição}

Ervas ou arbustos perenes, algumas vezes escandentes ou pequenas árvores; látex geralmente presente. Folhas geralmente opostas, às vezes em rosetas, pecioladas, raramente sésseis, base foliar com pseudoestípulas ou disco nodal, venação trinervada, pinada ou palmada, alvo-tomentosas na face abaxial. Capitulescência simples ou subcimosa, às vezes formando uma panícula tirsoide; capítulos radiados, heterógamos; invólucro geralmente subimbricado, com brácteas em muitas séries graduadas; receptáculo alveolado, raramente paleáceo. Flores do raio geralmente presentes, pistiladas, corola amarela, ocasionalmente avermelhada a púrpura ou alva, estilete com ramos alongados. Flores do disco bissexuais, corola tubulosa, usualmente amarela, raramente vermelha, púrpura ou alva; anteras com apêndice do conectivo mais longo que largo, base da antera calcarada, algumas vezes caudada, fimbriada ou sagitada; estilete com base glabra e ápice piloso. Cipselas geralmente prismáticas, (2-4)5-10-costadas, geralmente com tricomas tectores e glandulares; pápus duplo, série mais externa menor, de escamas, e a mais interna de cerdas maiores, algumas vezes com cerdas plumosas ou pápus ausente.

No Brasil, há registro de apenas um gênero (Liabum) e duas espécies (Liabum acuminatum Rusby e L. amplexicaule Poepp.), ambas com ocorrência no Acre (BFG, 2015; DILLON et al., 2009).

\section{Literatura recomendada}

BENTHAM, G. Compositae. In: BENTHAM, G.; HOOKER, J. D. (Ed.). Genera Plantarum. London: Reeve, 1873, v. 2, n. 1, p. 163-533.

BRAZIL FLORA GROUP -BFG. Growing knowledge: an overview of seed plant diversity in Brazil. Rodriguésia, Rio de Janeiro, v. 66, n. 4, p. 1085-1113, 2015. 
CARLQUIST, S. Tribal interrelationships and phylogeny of the Asteraceae. Aliso, Claremont, v. 8, p. 465-492, 1976.

CASSINI, H. Liabum. In: CUVIER, G. (Ed.). Dictionnaire des Sciences Naturelles. 2 ème éd. Paris. Le Normant, 1823. v. 26, p. 203-211.

CRONQUIST, A. Phylogeny and taxonomy of the Compositae. American Midland Naturalist, Notre Dame, v. 53, p. 478-511, 1955.

DILLON, M. O. et al. Liabeae. In: FUNK, V. A. et al. (Ed.). Systematics, Evolution and Biogeography of Compositae. Vienna: IAPT, 2009. p. 417-438.

FUNK, V. A.; ROBINSON, H.; DILLON, M.O. Tribe Liabeae. In: KADEREIT, J. W.; JEFFREY, C. (Ed.). The Families and Genera of Vascular Plant: v. VIII: Flowering Plants Eudicots: Asterales. Berlin: Springer, 2007. p. 175-180. HOFFMANN, O. Compositae. In: ENGLER, A.; PRANTL, K. Die Natürlichen Pflanzenfamilien. Leipzig: W. Engelmann, 1890. v. 4, p. 87-391.

ROBINSON, H. A generic review of the tribe Liabeae (Asteraceae). Washington: Smithsonian Institution Press, 1983a. p. 1-69. (Smithsonian Institution Press, v. 54).

ROBINSON, H. Studies in the Liabeae (Asteraceae). XVI. New taxa from Peru. Phytologia, Huntsville, v. 54, p. 62-65, 1983b.

ROBINSON, H. Notes on Sinclairia and Liabellum in Mesoamerica (Liabeae: Asteraceae). Phytologia, Huntsville, v. 69, p. 57-60, 1990a.

ROBINSON, H. A redelimitation of Microliabum Cabrera (Asteraceae: Liabeae). Systematic Botany, Kent, v. 15, n. 4, p. 736-744, 1990b.

ROBINSON, H. New species of Ferreyranthus and Munnozia from Peru (Liabeae: Asteraceae). Phytologia, Huntsville, v. 76, p. 19-23, 1994.

ROBINSON, H.; BRETTELL, R. D. Tribal revisions in the Asteraceae. III. A new tribe, Liabeae. Phytologia, Huntsville, v. 25, p. 404-407, 1973.

ROBINSON, H.; BRETTELL, R. D. Studies in the Liabeae (Asteraceae). II. Preliminary survey of the genera. Phytologia, Huntsville, v. 28, p. 43-63, 1974.

RYDBERG, P. A. Carduaceae: Liabeae, Neurolaeneae, Senecioneae (pars). North American Flora, New York, v. 34, n. 4, p. 289-360, 1927. 